\title{
FORMULATION AND EVALUATION OF IMPLANTABLE DRUG DELIVERY SYSTEM OF TEMOZOLOMIDE BY USING HYDROPHILIC POLYMER
}

\section{SINDHU V, BHAVYA S, SURESH KUMAR P, JEYABASKARAN M, PRAVEENKUMAR T, SD. YASMIN SULTHANA}

Department of Pharmaceutics, Browns College of Pharmacy, Khammam, Telangana, India. Email: sindhu95.vemula@gmail.com Received: 18 May 2017, Revised and Accepted: 31 May 2017

\section{ABSTRACT}

Objective: The present research study was carried out to formulate and evaluate the implants of temozolomide using hydrophilic polymer.

Methods: Temozolomide implants were formulated using extrusion method with different grades of carbopol. The powdered blend was evaluated for micromeritic properties such as angle of repose, bulk density, tapped density, Carr's index, and Hausner's ratio. The formulated implants were analyzed for drug content uniformity, thickness, weight variation, and short-term stability study. In vitro release study of implants was performed using $0.1 \mathrm{~N}$ hydrochloric acid, and it is maintained at $37^{\circ} \mathrm{C} \pm 0.5^{\circ} \mathrm{C}$.

Results: In vitro release study demonstrated that the release rate of temozolomide from the implant matrix was a function of concentration of the polymer. As the concentration of polymer was increased, drug release from the matrix was extended. The release of drug from all implant formulations was found to be uniform and was extended over a period of $12 \mathrm{hrs}$. The implant formulations were found sterile, uniform in weight and size. The drug content was found to be in the range of $97.2-101.33 \%$.

Conclusion: Drug interaction studies revealed that there were no chemical interactions between temozolomide and polymers used in the study. Short-term stability studies of implants revealed that implants were stable, and there were no significant changes in the physical appearance and drug content of the implant formulations. The results of the study demonstrated that implantable drug delivery system of temozolomide can be formulated using hydrophilic polymer.

Keywords: Carbopol, Cross linking agent, Hydrophilic polymer, Implants, Temozolomide.

(C) 2017 The Authors. Published by Innovare Academic Sciences Pvt Ltd. This is an open access article under the CC BY license (http://creativecommons. org/licenses/by/4. 0/) DOI: http://dx.doi.org/10.22159/ajpcr.2017.v10i11.20070

\section{INTRODUCTION}

The objective of the present study was to formulate and evaluate implants of temozolomide using hydrophilic polymers. Nowadays, cancer is the major cause of mortality. Although scientists have done great research to know the causes of cancer, and for the diagnosis and the treatment, still mortality rate is high because the exact cure was not found. Cancer treatment is one of the major challenges in modern science as the drug delivery to solid tumors is a challenge to develop more effective cancer therapies. Drugs administered orally must be protected from denaturation in the gastrointestinal tract and should be capable of absorption across the wall of the intestine. After absorption and entering into hepatic circulation, it must be resistant to hepatic enzymes. The rate of drug absorption and elimination should be within the therapeutic range [1]

Nowadays, controlled drug delivery has achieved the sustained zeroorder release of a drug substance over prolonged period of time. With the advancement in development and technology, various techniques such as osmotically driven pumps [2], matrices with controllable swelling [3] diffusion [4,5] or erosion rates [6], non-uniform drug loading profiles [7-9], multilayered matrices [10], and therapeutic molecule or protein in a schematic of a pulsatile or staggered fashion are used for formulating sustained release dosage forms. In the 1930s, a new system of sustained release implantable drug delivery system was administered by subcutaneous route was introduced [11]. Matrix systems are used as non-degradable implants. These systems consist of uniformly distributed drug throughout a solid non-biodegradable polymer [12]. Matrix systems rely on the diffusion of drug particles through non-degradable fibrous network of the polymer to achieve sustained release of the drug. The higher concentration of disintegrating agent within the matrix, greater would be the release of drug from the system [13]
Temozolomide is an oral alkylating agent used in the treatment of brain cancers and as first-line treatment for glioblastoma multiform and as a second-line treatment for astrocytoma. Temozolomide belongs to the class imidazotetrazines. These are organic polycyclic compounds containing an imidazole ring fused to tetrazine ring. Temozolomide is an imidazotetrazine derivative and an antineoplastic agent. It is a prodrug that has little to no pharmacological activity until it is hydrolyzed in vivo to 5-(3-methyltriazen-1-yl) imidazole-4-carboxamide (MTIC). After administration, temozolomide undergoes rapid, non-enzymatic hydrolysis at physiological pH to MTIC, which is the active form of the drug. About $38 \%$ of the administered temozolomide, total radioactive dose is recovered over 7 days. Elimination is by renal mechanism, $37.7 \%$ of drug is eliminated in urine and $0.8 \%$ in feces [14-17].

\section{METHODS}

Temozolomide was obtained as a gift sample from Alkem Laboratories Ltd., Mumbai, carbopol 931 was procured from Signet Chemical Corp., Mumbai, Maharashtra, India, acetic acid was procured from Loba Chemie, Mumbai, and glutaraldehyde solution was procured from S.D. Fine Chem. Ltd, Mumbai, Maharashtra, India.

\section{Preparation of implants using extrusion method}

Implants of temozolomide were prepared with different grades of carbopol as per the formula. The drug was dissolved in $5 \%$ acetic acid solution. Carbopol powder was added slowly to the drug solution, and it was allowed to soak for 10-15 minutes. The swollen mass so formed was mixed uniformly in a glass mortar and mixed thoroughly until it becomes a sticky dough mass. The dough mass was fed into the cylinder of the extruder and was extruded in the form of long rods through the nozzle. The rods were kept for drying overnight on a glass plate, and the rods were cut into 27 mm-sized implants. The implants were then dried at $40^{\circ} \mathrm{C}$. 
Cross linking of implants

About $25 \mathrm{ml}$ of $25 \%$ of glutaraldehyde solution was taken in $100 \mathrm{ml}$ beaker and was placed in an empty desiccator. A wire mesh containing implants was kept in a desiccator and was immediately closed. The implants were made to react with glutaraldehyde vapors for different time intervals ( $6 \mathrm{hrs}, 12 \mathrm{hrs}$, and $24 \mathrm{hrs}$ ). Then, they were removed and air-dried for 72 hrs. Hence, that complete reaction between the carbopol and glutaraldehyde should take place. Afterwards, the implants were kept in an open atmosphere for a week to make the residual glutaraldehyde gets evaporated. The cross linking was carried out at low temperature. The residual glutaraldehyde can also be removed using an aqueous $(2 \%)$ sodium metabisulfite solution and then immediately removed from it and placed in absolute alcohol bath (Table 1).

\section{Evaluation of pre-compression parameters of the powder blend}

The prepared powder formulation was subjected to measurement of angle of repose, bulk density, tapped density, Carr's compressibility index, and Hausner's ratio as per the standard procedure suggested $[18,19]$.

\section{Evaluation parameters for implants}

Uniformity of weight

This test is performed to maintain the uniformity of weight of each implant. This is done by weighing 20 implants at random, and average weight is calculated. Not more than two of the individual weights deviate from the average weight by more than the percentage, and none deviate by more than twice the percentage. The mean and standard deviation were determined and reported [20].

\section{Diameter of implants}

The length and diameter of implants from every batch were measured with the help of Vernier calipers. Three samples were taken for the study from each batch, and mean value was reported [21,22].

\section{Procedure for drug content uniformity test}

Drug content of implants from every batch was estimated. The implants were cut into small pieces and were taken into $50 \mathrm{ml}$ volumetric flask, $45 \mathrm{ml}$ of glacial acetic acid was added and shaken thoroughly to dissolve the drug, and the volume was made up to $50 \mathrm{ml}$ with glacial acetic acid. This solution was suitably diluted with glacial acetic acid and assayed for temozolomide content by measuring the absorbance at $330 \mathrm{~nm}$. Temozolomide contents were calculated, using the standard calibration curve [20].

\section{$\%$ swelling index}

To study swelling index, the implant formulations were immersed into swelling solution phosphate buffer $\mathrm{pH}$ 7. The implants were placed in swelling solution and weight of implant was measured after $1 \mathrm{hr}$, and the excess of solution was removed gently by tapping the surface with a dry piece of filter paper [23]. The degree of swelling for each implant formulation at given time was calculated using the following equation:

$$
\mathrm{H}=\frac{\mathrm{W}_{\mathrm{t}}-\mathrm{W}_{0}}{\mathrm{~W}_{0}} \times 100
$$

Where, $W_{t}$ and $W_{0}$ are the sample's weight at any given time and in the dry state, respectively.

\section{In vitro dissolution studies}

Dissolution test was carried out using USP XXIV (model DISSO, M/s. Lab India, Hyderabad) rotating paddle method (apparatus 2). $0.1 \mathrm{~N}$ hydrochloric acid was used as dissolution medium (900 ml), and the stirring rate was maintained at $50 \mathrm{rpm}$ and temperature at $37^{\circ} \mathrm{C} \pm 0.5^{\circ} \mathrm{C}$. Samples of $5 \mathrm{ml}$ were withdrawn at predetermined time intervals, filtered, and replaced with $5 \mathrm{ml}$ of fresh dissolution medium. The collected samples were suitably diluted with dissolution fluid wherever necessary and were analyzed for the temozolomide at $330 \mathrm{~nm}$ using a double-beam ultraviolet spectrophotometer (Shimadzu-2000). Each dissolution study was performed for three times, and the mean values were taken [24].

\section{Stability study}

The purpose of stability testing (the International Conference on Harmonization [ICH], 2004) is to provide evidence on how the quality of a drug substance or drug product varies with time under the influence of a variety of environmental factors such as temperature, humidity, and light, enabling recommended storage conditions, retest periods, and shelf lives. The ICH guidelines stability studies were carried out at $25^{\circ} \mathrm{C} / 75 \% \mathrm{RH}$ for the selected formulation for 3 months. The selected formulations were wrapped in butter paper, were then stored at $37^{\circ} \mathrm{C} / 75 \% \mathrm{RH}$ for 3 months, and evaluated for their physical appearance and drug content at specified intervals of time.

\section{Drug polymer interaction study}

The IR spectra of temozolomide and its formulations were obtained by $\mathrm{KBr}$ Pellet method using Perkin Elmer Fourier transform infrared (FTIR) series model 1615 spectrometer. The subdermal implants of temozolomide prepared with carbopol were tested for compatibility of the drug with the excipients by IR study.

\section{RESULTS AND DISCUSSION}

\section{Pre-compression evaluation parameters of temozolomide} formulation blend

The powder blends were prepared by mixing of various ingredients mentioned and used for characterization of various flow properties of powder. The bulk density of all the formulations was found to be in the range of $0.48 \pm 0.05$ to $0.58 \pm 0.06\left(\mathrm{~g} / \mathrm{cm}^{3}\right)$ showing that the powder has good flow properties. The tapped density of all the formulations was found to be in the range of $0.57 \pm 0.01$ to $0.69 \pm 0.04$. The compressibility index of all the formulations was found to be ranging between $16.21 \pm 0.06$ and $17.97 \pm 0.02$. All the formulations have shown the Hausner ratio ranging between $0.64 \pm 0.03$ and $1.17 \pm 0.02$, indicating the powder has good flow properties (Table 2).

\section{Evaluation parameters of temozolomide implants}

\section{Physical characteristics}

The physical characteristics of temozolomide implants (F1-F9) such as weight variation and drug content were determined, and results of the formulations (F1-F9) found to be within the limits specified in official books.

\section{Drug content}

All the implant formulations shown good uniformity in drug content and they contain $97.2-101.33 \%$ of temozolomide which is within the specified limit.

Table 1: Formulation composition for implants

\begin{tabular}{llllllllll}
\hline Formulation code & F1 & F2 & F3 & F4 & F5 & F6 & F7 & F8 & F9 \\
\hline Temozolomide (mg) & 20 & 20 & 20 & 20 & 20 & 20 & 20 & 20 & 20 \\
Carbopol 931 (mg) & 200 & 400 & 600 & - & - & - & - & - & - \\
Carbopol 934 (mg) & - & - & - & 200 & 400 & 600 & - & - \\
Carbopol 971 (mg) & - & - & - & - & - & - & 200 & 400 & 600 \\
5\% acetic acid (ml) & 5 & 5 & 5 & 5 & 5 & 5 & 5 & 5 & 5 \\
25\% glutaraldehyde solution & Qs & Qs & Qs & Qs & Qs & Qs & Qs & Qs & Qs \\
\hline
\end{tabular}




\section{Diameters of implants}

The diameter determined for formulated implants is tabulated in Table 3. Implants mean diameters were almost uniform in all the batches of implants formulations and were found to be in the range of $1.05-1.70 \mathrm{~mm}$.

\section{Uniformity of weight}

The weight variations for all formulations are shown in Table 3. All the implants passed weight variation test as the $\%$ weight variation was within the pharmacopoeial limits. The weights of all the implants formulations were found to be in the range of $50 \pm 5 \mathrm{mg}$.

\section{$\%$ swelling index}

The $\%$ swelling index of the prepared implants ranged from $87-146 \%$.

\section{In vitro drug release}

Dissolution test was carried out using USP XXIV (model DISSO, M/s. Lab India, Hyderabad) rotating paddle method (apparatus 2) at 50 rpm using $0.1 \mathrm{~N}$ hydrochloric acid as dissolution medium. Each dissolution study was performed for three times, and the mean values were taken. The in vitro dissolution studies of implants of temozolomide were conducted in simulated gastric fluid $0.1 \mathrm{~N} \mathrm{Hcl}$ for $12 \mathrm{hrs}$. Formulations F1-F3 were prepared with carbopol 931. Formulation F1 showed complete drug release within 2 hrs, whereas F2 and F3 showed complete drug release in 3 and $4 \mathrm{hrs}$, respectively. The implants were unable to retain their shape and integrity for not more than $4 \mathrm{hrs}$. Hence, they were not considered. The formulations prepared with carbopol 934 retarded drug release. Formulations F4 and F5 showed complete drug release with in 5 and 6 hrs. Formulations F4 and F5 were unable to retard drug release up to desired time period. F6 formulation retarded the drug release up to $12 \mathrm{hrs}$, and it showed a maximum of $89.87 \mathrm{in} 12 \mathrm{hrs}$.

Formulations F7-F9 were prepared with carbopol 971. Formulations F7, F8, and F9 were retarded the drug release for more than 12 hrs. The formulation F7 was shown $98.78 \%$ in $12 \mathrm{hrs}$, whereas the formulation F8 and F9 showed only $84 \%$ and $78 \%$ of drug release in 12 hrs, respectively. It was observed that as the concentration of polymer increases, the drug release was also retarded. Initially, the formulations

Table 2: Micromeritic properties of powder blend

\begin{tabular}{lllll}
\hline $\begin{array}{l}\text { Formulation } \\
\text { code }\end{array}$ & $\begin{array}{l}\text { Bulk } \\
\text { density }\end{array}$ & $\begin{array}{l}\text { Tapped } \\
\text { density }\end{array}$ & $\begin{array}{l}\text { Compressibility } \\
\text { index }\end{array}$ & $\begin{array}{l}\text { Hausner's } \\
\text { ratio }\end{array}$ \\
\hline F1 & $0.49 \pm 0.07$ & $0.57 \pm 0.01$ & $16.21 \pm 0.06$ & $0.86 \pm 0.06$ \\
F2 & $0.56 \pm 0.06$ & $0.62 \pm 0.05$ & $16.87 \pm 0.05$ & $0.98 \pm 0.05$ \\
F3 & $0.52 \pm 0.03$ & $0.68 \pm 0.07$ & $17.11 \pm 0.01$ & $0.64 \pm 0.03$ \\
F4 & $0.54 \pm 0.04$ & $0.64 \pm 0.08$ & $17.67 \pm 0.08$ & $1.12 \pm 0.04$ \\
F5 & $0.53 \pm 0.06$ & $0.67 \pm 0.03$ & $16.92 \pm 0.04$ & $1.2 \pm 0.08$ \\
F6 & $0.56 \pm 0.05$ & $0.66 \pm 0.06$ & $17.65 \pm 0.09$ & $1.06 \pm 0.09$ \\
F7 & $0.58 \pm 0.06$ & $0.69 \pm 0.04$ & $16.43 \pm 0.05$ & $0.76 \pm 0.03$ \\
F8 & $0.48 \pm 0.05$ & $0.57 \pm 0.02$ & $17.97 \pm 0.02$ & $1.15 \pm 0.09$ \\
F9 & $0.54 \pm 0.08$ & $0.62 \pm 0.03$ & $17.54 \pm 0.09$ & $1.17 \pm 0.02$ \\
\hline
\end{tabular}

containing low concentration and low viscosity showed $50-100 \%$ drug release within 4-6 hrs. Formulations containing high viscosity and high concentration were able to retard drug release for more than $12 \mathrm{hrs}$. Hence, based on dissolution study, formulation F7 is considered as the best formulation (Table 4 and Figs. 1-3).

\section{Stability studies}

Stability studies were carried out at $25^{\circ} \mathrm{C} / 75 \% \mathrm{RH}$ and $37^{\circ} \mathrm{C} / 75 \% \mathrm{RH}$ for the selected formulation for 3 months. The selected formulations

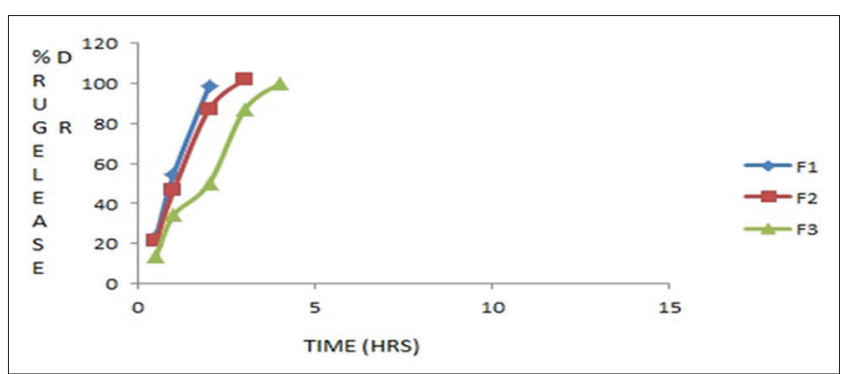

Fig. 1: In vitro drug release of implants with carbopol 931 (F1, F2, and F3)

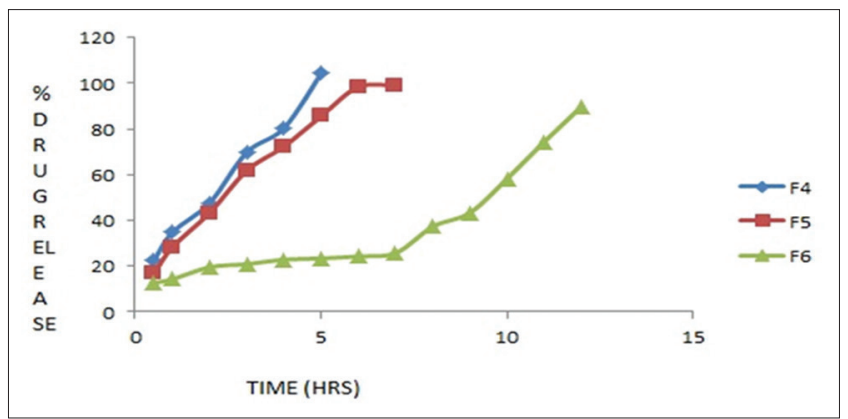

Fig. 2: In vitro drug release of implants with carbopol 934 (F4, F5, and F6)

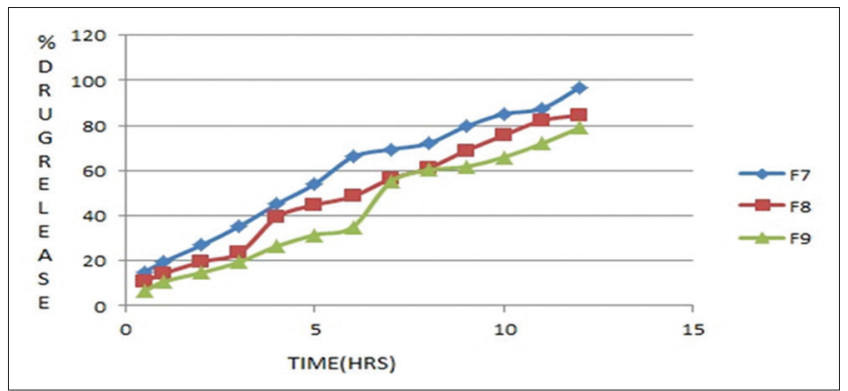

Fig. 3: In vitro drug release of implants with carbopol 971 (F7, F8, and F9)

Table 3: Evaluations of physical parameters of implants

\begin{tabular}{|c|c|c|c|c|}
\hline Formulation code & Weight variation $(\mathrm{mg})( \pm \mathrm{SD})$ & Drug content $(\%)( \pm S D)$ & $\begin{array}{l}\% \text { swelling } \\
\text { index }\end{array}$ & Diameter of implants \\
\hline F1 & $55 \pm 0.04$ & $100.8 \pm 0.01$ & 89 & 1.02 \\
\hline F2 & $51 \pm 0.01$ & $97.8 \pm 0.02$ & 112 & 1.54 \\
\hline F3 & $49 \pm 0.02$ & $99.9 \pm 0.09$ & 134 & 1.36 \\
\hline $\mathrm{F} 4$ & $46 \pm 0.05$ & $101.33 \pm 0.03$ & 104 & 1.28 \\
\hline F5 & $51 \pm 0.08$ & $100.07 \pm 0.08$ & 114 & 1.07 \\
\hline F6 & $53 \pm 0.09$ & $95.6 \pm 0.09$ & 145 & 1.67 \\
\hline F7 & $46 \pm 0.01$ & $98.9 \pm 0.07$ & 87 & 1.74 \\
\hline F8 & $55 \pm 0.08$ & $100.2 \pm 0.04$ & 134 & 1.48 \\
\hline F9 & $51 \pm 0.07$ & $99.8 \pm 0.08$ & 176 & 1.59 \\
\hline
\end{tabular}

SD: Standard deviation 
were wrapped in butter paper and were then evaluated for their physical appearance and drug content at specified intervals of time. By observing the stability studies, it is concluded that the optimized formulation is stable through the entire period of 3 months and the drug release profile is also intact throughout the time being (Table 5).

Table 4: Drug release profile of temozolomide implants

\begin{tabular}{|c|c|c|c|c|c|c|c|c|c|}
\hline \multirow{2}{*}{$\begin{array}{l}\text { Time } \\
\text { (hrs) }\end{array}$} & \multicolumn{9}{|c|}{$\%$ cumulative drug release } \\
\hline & F1 & F2 & F3 & F4 & F5 & F6 & F7 & F8 & F9 \\
\hline 0.5 & $23.22 \pm 0.06$ & $21.33 \pm 0.07$ & $13.80 \pm 0.02$ & $22.44 \pm 0.01$ & $16.88 \pm 0.07$ & $12.66 \pm 0.08$ & $15.16 \pm 0.09$ & $10.88 \pm 0.01$ & $6.69 \pm 0.07$ \\
\hline 2 & $98.59 \pm 0.08$ & $87.04 \pm 0.05$ & $50.01 \pm 0.04$ & $47.70 \pm 0.07$ & $43.41 \pm 0.09$ & $19.59 \pm 0.08$ & $26.99 \pm 0.09$ & $19.58 \pm 0.05$ & $14.76 \pm 0.06$ \\
\hline 3 & & $101.85 \pm 0.09$ & $86.79 \pm 0.09$ & $69.85 \pm 0.08$ & $61.91 \pm 0.03$ & $20.92 \pm 0.05$ & $35.34 \pm 0.02$ & $23.60 \pm 0.02$ & $19.51 \pm 0.09$ \\
\hline 4 & & & $99.83 \pm 0.02$ & $80.46 \pm 0.09$ & $72.42 \pm 0.02$ & $22.92 \pm 0.06$ & $45.25 \pm 0.06$ & $39.54 \pm 0.04$ & $26.58 \pm 0.08$ \\
\hline 5 & & & & $104.40 \pm 0.02$ & $85.71 \pm 0.05$ & $23.38 \pm 0.02$ & $54.11 \pm 0.07$ & $44.76 \pm 0.09$ & $31.54 \pm 0.01$ \\
\hline 6 & & & & & $98.47 \pm 0.09$ & $24.29 \pm 0.03$ & $66.08 \pm 0.04$ & $48.61 \pm 0.08$ & $35.04 \pm 0.03$ \\
\hline 7 & & & & & $98.91 \pm 0.06$ & $25.77 \pm 0.09$ & $69.49 \pm 0.05$ & $56.38 \pm 0.02$ & $54.96 \pm 0.07$ \\
\hline 8 & & & & & & $37.34 \pm 0.06$ & $72.09 \pm 0.08$ & $61.13 \pm 0.09$ & $60.26 \pm 0.09$ \\
\hline 9 & & & & & & $43.41 \pm 0.03$ & $79.71 \pm 0.05$ & $68.96 \pm 0.08$ & $61.75 \pm 0.02$ \\
\hline 10 & & & & & & $58.31 \pm 0.08$ & $85.14 \pm 0.02$ & $75.72 \pm 0.07$ & $65.97 \pm 0.05$ \\
\hline 11 & & & & & & $74.51 \pm 0.09$ & $87.54 \pm 0.09$ & $82.24 \pm 0.03$ & $71.99 \pm 0.07$ \\
\hline 12 & & & & & & $89.87 \pm 0.04$ & $98.78 \pm 0.09$ & $84.58 \pm 0.06$ & $78.99 \pm 0.09$ \\
\hline
\end{tabular}

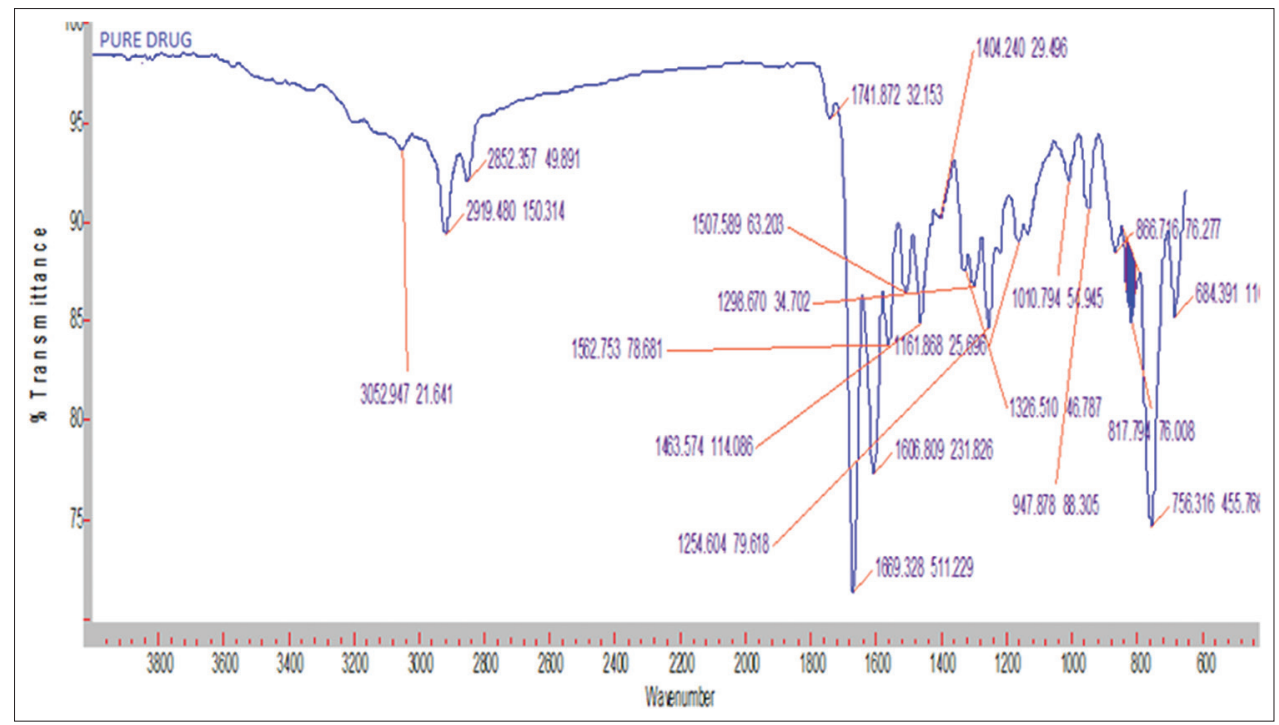

Fig. 4: Fourier transform infrared spectra of pure drug

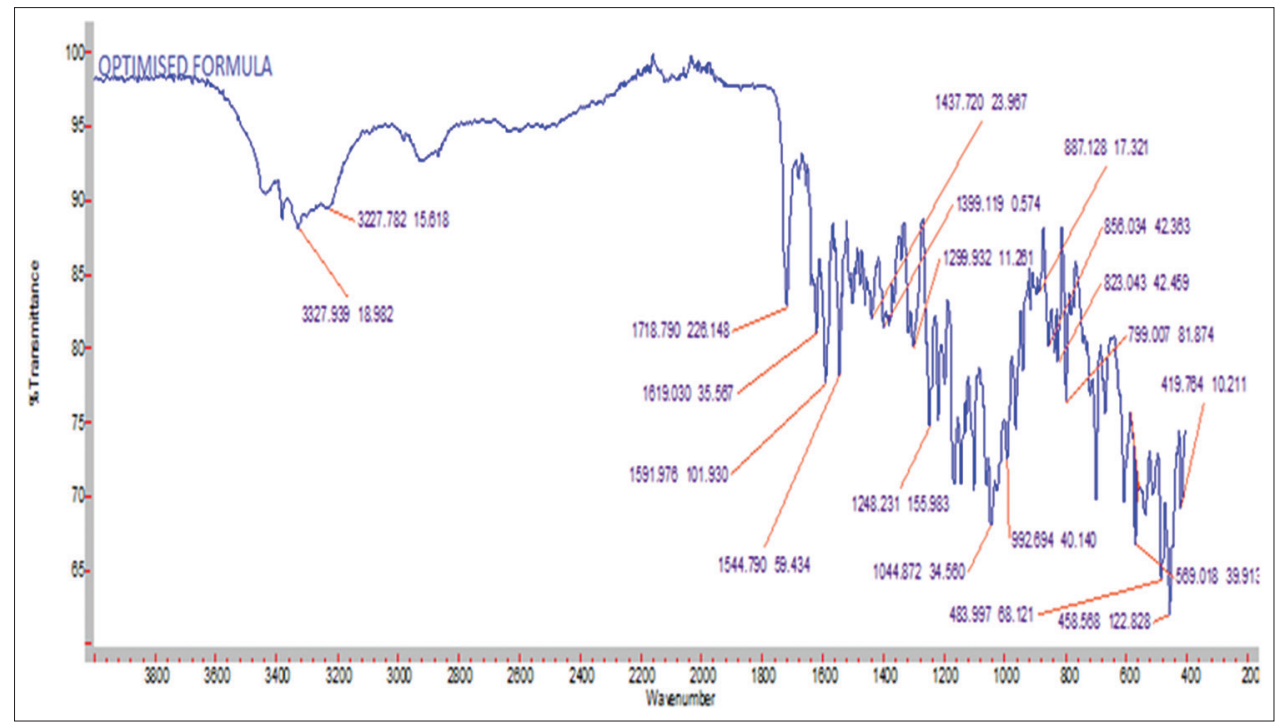

Fig. 5: Fourier transform infrared spectra of optimized formulation 
Table 5: Stability studies for optimized formulation (F7)

\begin{tabular}{llll}
\hline S.No. & $\begin{array}{l}\text { Optimized } \\
\text { formulation (F3) } \\
\text { duration (months) }\end{array}$ & $\mathbf{2 5}^{\circ} \mathbf{C}(\mathbf{7 5 \%} \mathbf{R H})$ & $\mathbf{3 7}^{\circ} \mathbf{C}(\mathbf{7 5 \%} \mathbf{R H})$ \\
\hline 1 & 1 & 97.85 & \\
2 & 2 & 97.35 & 97.92 \\
3 & 3 & 97.10 & 97.80 \\
\hline
\end{tabular}

\section{Compatibility studies by FTIR}

The drug and excipient compatibility studies were carried out by FTIR study. The study showed peaks for the corresponding functional groups in temozolomide. When the study was carried out with temozolomide and polymers, there was no major changes in the peaks. By observing the above FTIR spectrums, there is no difference between internal structures and confirmation of these samples at the molecular level. It was shown that there is no interaction between the drug and polymers used (Figs. 4 and 5)

\section{CONCLUSION}

Temozolomide implants were prepared using Hydrophillic polymer. Nine formulations were prepared using carbopol 931, carbopol 934, and carbopol 971. The pre-formulation parameters were carried out for the powder blend. All the formulations results were within the limits. Implants were prepared using extrusion method. The physical parameters of all the formulations were found to be within the limit. The in vitro dissolution test was conducted to all the nine formulations, among them, the formulation F7 was shown 98.78\% drug release in 12 hrs, whereas the others shown less drug release. FTIR studies revealed that there were no chemical interactions between temozolomide and the polymers used in the study. Short-term stability studies of promising formulations indicated that there were no significant changes in appearance and drug content of implants.

\section{REFERENCES}

1. Yea W, Chie W. Novel Drug Delivery System. $2^{\text {nd }}$ ed. New York, NY: Marcel Dekker, Inc.; 1992. p. 269.

2. Sefton MV. Implantable pumps. CRC Crit Rev Biomed Eng 1987; 14:201-40.

3. Conte U, Maggi L. A flexible technology for the linear, pulsatile and delayed release of drugs, allowing for easy accommodation of difficult in vitro targets. J Control Release 2000;64(1-3):263-8.

4. Lee ES, Kim SW, Kim SH, Cardinal JR, Jacobs H. Drug release from hydrogel devices with rate-controlling barriers. J Memb Sci 1980;7:293-303.

5. Korsmeyer RW, Peppas NA. Macromolecular and modelling aspects of swelling- controlled systems. In: Roseman TJ, Mansdorf SZ, editors. Controlled Release Delivery Systems. New York: Marcel Dekker; 1983. p. 77-90

6. Yang L, Fassihi R. Modulation of diclofenac release from a totally soluble controlled release. Drug delivery system. J Control Release 1997;44:135-40.

7. Hildgen P, McMullen JN. A new gradient matrix: Formulation and characterization. J Control Release 1995;34:263-71.

8. Lu S, Anseth KS. Photopolymerization of multilaminated poly(HEMA) hydrogels for controlled release. J Control Release 1999;57(3):291-300.

9. Lu S, Ramirez F, Anseth K. Photopolymerized, multilaminated matrix devices with optimized non-uniform initial concentration profiles to control drug release. J Pharm Sci 2000;89:45-51.

10. Qiu Y, Chidambaram N, Flood K. Design and evaluation of layered diffusional matrices for zero-order sustained-release. J Control Release 1998;51(2-3):123-30.

11. Danckwerts M, Fassihi A. Implantable controlled release drug delivery systems: A review. Drug Dev Ind Pharm 1991;17:1465-502.

12. Dash AK, Cudworth GC $2^{\text {nd }}$. Therapeutic applications of implantable drug delivery systems. J Pharmacol Toxicol Methods 1998;40(1):1-12.

13. Higuchi $T$. Rate of release of medicaments from ointment bases containing drugs in suspension. J Pharm Sci 1961;50:874-5.

14. Overington JP, Al-Lazikani B, Hopkins AL. How many drug targets are there? Nat Rev Drug Discov 2006;5(12):993-6.

15. Imming $P$, Sinning $C$, Meyer A. Drugs, their targets and the nature and number of drug targets. Nat Rev Drug Discov 2006;5(10):821-34.

16. Zaremba T, Curtin NJ. PARP inhibitor development for systemic cancer targeting anticancer agents. Med Chem 2007;7(5):515-23.

17. Dinca EB, Sarkaria JN, Schroeder MA, Carlson BL, Voicu R, Gupta N, et al. Bioluminescence monitoring of intracranial glioblastoma xenograft: Response to primary and salvage temozolomide therapy. J Neurosurg 2007;107(3):610-6.

18. Nalneesh B. Formulation and evaluation of sustained- release matrix tablets of nitrofurantoin. Int J Chem Technol Res 2013;5(1):491-501.

19. Lachman L, Lieberman HA, Kanig JL. The Theory and Practice of Industrial Pharmacy. $3^{\text {rd }}$ ed. Vargheese Publishing House; 1991.

20. Jameela SR, Kumary TV, Lal AV, Jayakrishnan A. Progesterone-loaded chitosan microspheres: A long acting biodegradable controlled delivery system. J Control Release 1998;52(1-2):17-24.

21. Islam $\mathrm{S}$, Islam $\mathrm{S}$, Urmi $\mathrm{AB}$. Observation of the release of aspirin from gelatin-sodium alginate polymeric implant. J Chem Pharm Res 2012;4(12):5149-56.

22. Saparia B, Murthy RS, Solanki A. Preparation and evaluation of chloroquine phosphate microspheres using cross linked gelatin for long term drug delivery. Indian J Pharm Sci 2002;64:48-52.

23. Karina CR, Riesta P, Esti H. Preparation and evaluation of ciprofloxacin implants using bovine hydroxyapatite-chitosan composite and glutaraldehyde for osteomyelitis. Int J Pharm Pharm Sci 2016;8(1):45-51.

24. Brahmanker DM, Jaiswal SB. Biopharmaceutics and Pharmacokinetics: A Treatise. $1^{\text {st }}$ ed. New Delhi: Vallabh Prakashan; 1995. 